\title{
CARACTERIZAÇÃO BIOMÉTRICA E RESPOSTAS FISIOLÓGICAS DE DIÁSPOROS DE MURUCIZEIRO A TRATAMENTOS PARA SUPERAÇÃO DA DORMÊNCIA ${ }^{1}$
}

\author{
JOSÉ EDMAR URANO DE CARVALHO² \& WALNICE MARIA OLIVEIRA DO NASCIMENTO
}

RESUMO- Diásporos (pirênios) de Byrsonima crassifolia (L.) H.B.K., dos clones Cristo, Santarém 2 e Tocantins 1, do Banco de Germoplasma da Embrapa Amazônia Oriental, foram caracterizados e submetidos a tratamentos pré-germinativos com o objetivo de aumentar a porcentagem e acelerar a germinação das sementes. Na caracterização, foram considerados os seguintes aspectos: massa, comprimento, largura, número de sementes e de lóculos por pirênio e espessura do endocarpo. Os tratamentos para superação da dormência consistiram em: a) pré-embebição dos pirênios em solução de ácido giberélico $\left(500 \mathrm{mg} \mathrm{L}^{-1}\right)$; b) pré-embebição em água seguida de fratura no endocarpo, e c) pré-embebição em solução de ácido giberélico com posterior fratura do endocarpo. Um tratamento-testemunha, representado por pirênios não submetidos a tratamento pré-germinativo, foi acrescentado para fins de comparação. Os pirênios dos três clones, com grande frequência, contêm mais de uma semente. A presença de pirênios desprovidos de sementes foi de apenas $1 \%$ nos clones Cristo e Santarém 2 e de 4\% no clone Tocantins 1 . Os diásporos do clone Cristo apresentaram maior massa e maiores dimensões. Em termos de número médio de sementes por pirênio, observaram-se valores semelhante nos clones Cristo $(1,7)$ e Santarém $2(1,8)$, enquanto esse valor foi menor no clone Tocantins $1(1,3)$. Os três clones apresentaram endocarpo com espessura semelhante. Os tratamentos pré-germinativos proporcionaram aumentos na porcentagem de germinação e reduções no tempo médio de germinação, com respostas mais expressivas quando os pirênios foram previamente embebidos em solução de ácido giberélico ou em água e, posteriormente, submetidos à fratura do endocarpo.

Termos para indexação: Byrsonima crassifolia, fruta tropical, germinação.

\section{BIOMETRIC CHARACTERIZATION AND PHYSIOLOGICAL RESPONSES OF MURUCI TREE DIASPORES TO TREATMENTS FOR OVERCOMING DORMANCY}

\begin{abstract}
Diaspores (pyrenes) of Byrsonima crassifolia (L.) H.B.K., of Cristo, Santarém 2 and Tocantins 1 clones, of the Embrapa Eastern Amazon Germplasm Bank, were characterized and subjected to pre-germinative treatments in order to increase the percentage and accelerating germination of seeds. In characterization, the following aspects were considered: weight, length, width, number of seeds and locules per pyrene and endocarp thickness. Treatments to overcome dormancy consisted of: a) pre-soaking the diaspores in a solution of gibberellic acid $\left(500 \mathrm{mg} \mathrm{L}^{-1}\right)$, b) pre-soaking in water followed by fractures in the endocarp, and c) pre-soaked in gibberellic acid with subsequent fracture of the endocarp. A control treatment, represented by pyrenes not submitted to treatment for overcome dormancy, was added for comparison purposes. The diaspores of the three clones, with most frequency, contain more than one seed. The presence of seedless pyrenes was only $1 \%$ in Cristo and Santarém 1 clones. On the other hand, in the Tocantins 1 clone the proportion of seedless pyrenes was $4 \%$. The Christ clone diaspores showed higher mass and larger size than the other two clones. In terms of average number of seeds per pyrene similar values were observed in Christ (1.7) and Santarém 2 (1.8) clones, while this value was lower in Tocantins 1 (1.3) clone. The three clones showed similar endocarp thickness. The pre-germination treatments induced increases in germination percentage and reductions in mean time to germination, with more significant responses when the pyrenes were previously soaked in gibberellic acid solution or water and then subjected to the fracture of the endocarp. Index terms: Byrsonima crassifolia, tropical fruit, germination.
\end{abstract}

1(Trabalho 240-12). Recebido em: 28-08-2012. Aceito para publicação em: 06-09-2013.

${ }^{2} \mathrm{Eng}^{\mathrm{o}}$ Agronomo. Pesquisador Embrapa Amazônia Oriental. E-mai: jose.urano-carvalho@embrapa.br

${ }^{3}$ Eng $^{a}$ Agronoma. Pesquisadora da Embrapa Amazônia Oriental. E-mail: walnice.nascimento@embrapa.br 


\section{INTRODUÇÃO}

O gênero Byrsonima engloba diversas espécies frutíferas conhecidas popularmente na Amazônia Brasileira como murucizeiro e nas demais regiões do Brasil como muricizeiro. B. crassifolia (L.) H.B.K., que tem como centro de origem e de diversidade genética a Amazônia Brasileira e que se encontra amplamente distribuída na América tropical, constitui-se na espécie mais importante, não só por ser a mais cultivada como também por apresentar frutos de melhor qualidade para o consumo (SOUZA et al., 2006; CAVALCANTE, 2010). Quando os primeiros exploradores europeus adentraram as terras americanas no final do século 15 , a espécie $B$. crassifolia (L.) H.B.K já era incipientemente cultivada e encontrava-se em estado semidomesticado (CLEMENT,1999).

O muruci é um fruto carnoso, do tipo drupoide, com formato globoso ou oblongo, oriundo de ovário tricarpelado, contendo cada carpelo um óvulo. É consumido como fruta fresca ou utilizado na elaboração de refresco, sorvete, doce em pasta, compota, licor e mesmo em pratos salgados, como recheio de carnes ou em sopas (BARROSO et al., 1999; CAVAlCANTE, 2010). Constitui-se em alimento de boa qualidade nutricional e contém em sua composição diversos compostos voláteis, como o etanol, o hexanoato de butilo, ácido butanoico, ácido hexanoico e butirato de metilo, responsáveis pelo aroma peculiar da fruta (ALVES; FRANCO, 2003). Além disso, é rico em polifenois e flavonoides, o que lhe confere grande capacidade antioxidante, podendo, portanto, ser enquadrado no grupo de alimentos funcionais (SILVA et al., 2007; SOUZA et al., 2008).

Na propagação sexuada do murucizeiro, a unidade de reprodução é representada pelo volumoso pirênio (diásporo), popularmente denominado de caroço, que representa, em média, $16,7 \%$ da massa do fruto e geralmente contém entre uma e três sementes, embora eventualmente possam ser desprovidos de sementes (CARVALHO; MULLER, 2005; CARVALHO; NASCIMENTO, 2008).

A germinação de sementes de muruci é lenta e desuniforme devido às restrições impostas pelo espesso e córneo endocarpo que impõe resistência mecânica à expansão do embrião. Além disso, considerável proporção de sementes apresenta dormência fisiológica, que pode ser superada pelo ácido giberélico. Dentro de cada lote, existe parcela variável de pirênios em que o endocarpo não oferece resistência à germinação, e as sementes não têm dormência, e outra parcela em que a resistência à germinação é imposta somente pelo endocarpo (CARVALHO; NASCIMENTO, 2008).

Tratamentos pré-germinativos dos diásporos envolvendo a escarificação ácida ou mecânica do endocarpo não têm logrado sucesso em promover a germinação de sementes de $B$. crassifolia (L.) H.B.K., assim como de outras espécies do mesmo gênero. No caso particular da escarificação com ácido sulfúrico concentrado, os efeitos são quase sempre deletérios, reduzindo drasticamente a porcentagem de germinação, pois o ácido penetra facilmente através do endocarpo e do delgado tegumento, provocando lesões graves no embrião, as quais redundam em perda da viabilidade (ALBERTO et al., 2011; NASCIMENTO et al., 2011).

Em diásporos de muruci do clone Açu, elevadas porcentagens de germinação e redução substancial no tempo requerido para a germinação foram obtidas quando os pirênios foram préembebidos em água ou em solução de ácido giberélico e, em seguida, submetidos à fratura do endocarpo por compressão. Aumentos significativos na porcentagem de germinação, porém de menor magnitude, também foram verificados quando os pirênios foram simplesmente pré-embebidos em solução de ácido giberélico, sem posterior fratura no endocarpo (CARVALHO; NASCIMENTO, 2008).

Este trabalho teve como objetivos caracterizar morfometricamente os pirênios e verificar os efeitos de tratamentos pré-germinativos sobre a germinação e a dormência de sementes de três clones de murucizeiro.

\section{MATERIAL E MÉTODOS}

Foram utilizados diásporos dos clones Cristo, Santarém 2 e Tocantins 1, do Banco de Germoplasma de Murucizeiro da Embrapa Amazônia Oriental, estabelecido na sede dessa instituição, em Belém-PA, provenientes de frutos coletados no solo no dia em que se desprenderam naturalmente da planta-mãe. Os frutos dos três clones foram coletados no mesmo dia e, após a coleta, foram acondicionados em recipientes abertos e mantidos durante 48 horas nas condições de ambiente natural de Belém (temperatura média de $26,8{ }^{\circ} \mathrm{C}$ e umidade relativa do ar de $86,0 \%$ ), para que atingissem o ponto ideal de maturação para consumo. Nesse ponto, a porção comestível, que corresponde ao mesocarpo, apresenta-se com consistência mole, o que facilita sobremaneira o despolpamento, que foi efetuado atritando-se os frutos sobre a superfície de uma peneira com tela de arame galvanizado, sob fluxo contínuo de água, até que os pirênios se apresentassem completamente 
desprovidos de resíduos de polpa. Em seguida, foram enxugados superficialmente com papel-toalha, dispostos em camada única e submetidos à secagem, durante dez dias, em uma sala com temperatura de $25 \pm 3{ }^{\circ} \mathrm{C}$ e umidade relativa do ar de $48 \pm 5 \%$. Esse procedimento de secagem possibilitou a redução do teor de água dos pirênios de $24,0 \pm 0,5 \%$ para níveis entre 7,0 e 7,5\%. Imediatamente após a secagem, retiraram-se amostras de pirênios de cada clone para a caracterização e para a aplicação dos tratamentos pré-germinativos.

As características morfométricas foram determinadas com base em cinco amostras de 20 pirênios por clone, considerando-se os seguintes aspectos: massa, comprimento e largura dos pirênios; espessura da parede externa do endocarpo e número de sementes e de lóculos por pirênio. A frequência do número de sementes foi baseada em uma amostra de 100 pirênios.

Os tratamentos pré-germinativos consistiram naqueles utilizados por Carvalho e Nascimento (2008), que se mostraram eficientes para a superação da dormência de sementes de muruci do clone Açu, quais sejam: a) pré-embebição em água seguida de fratura do endocarpo por compressão; b) pré-embebição dos pirênios em solução de ácido giberélico (500 mg L $\left.{ }^{-1}\right)$, durante 24 horas; c) pré-embebição dos pirênios, durante 24 horas, em solução de ácido giberélico (500 mg L-1), seguida de fratura do endocarpo por compressão. Para cada clone, adicionou-se um tratamentotestemunha representado por pirênios não submetidos a tratamento pré-germinativo.

A fratura do endocarpo foi obtida comprimindo-se cada pirênio, no sentido do ápice para a base, em uma morsa de bancada. Durante essa operação, nenhum pirênio foi descartado, mesmo quando se suspeitava que as sementes pudessem ter sofrido injúrias mecânicas. Tal procedimento foi adotado para se verificar a eficácia do método de compressão, conforme recomendado por Carvalho e Nascimento (2008).

Os testes de germinação foram conduzidos nas condições de ambiente natural de Belém, com quatro repetições de 50 pirênios semeados a $1 \mathrm{~cm}$ de profundidade em substrato constituído da mistura de areia com pó de serragem, na proporção volumétrica de 1:1. Esse substrato foi previamente esterilizado em água fervente durante duas horas e, por ocasião dos testes de germinação, mantido na capacidade de campo, com irrigações efetuadas em turnos de 48 horas. $\mathrm{O}$ número de sementes germinadas em cada parcela foi anotado diariamente, para fins de estimativa do tempo médio de germinação e para a elaboração das curvas de germinação. O tempo médio de germinação, expressado em dias, foi calculado de acordo com a equação:

$\mathrm{TMG}=\frac{N_{1} T_{1}+N_{2} T_{2}+\ldots+N_{n} T_{n}}{N_{1}+N_{2}+\ldots+N_{n}}$

Nessa equação, TMG é o tempo médio de germinação das sementes que germinaram no prazo de 40 dias; $\mathrm{N}_{1}, \mathrm{~N}_{2}$ e $\mathrm{N}_{\mathrm{n}}$ é o número de sementes germinadas nos tempos $\mathrm{T}_{1}, \mathrm{~T}_{2}$ e $\mathrm{T}_{\mathrm{n}}$.

Ao final dos testes de germinação, os pirênios em que não ocorreu a germinação de nenhuma semente foram removidos do substrato e efetuou-se a extração de uma semente de cada pirênio para a avaliação da viabilidade, pelo teste de tetrazólio. Os embriões foram imersos durante quatro horas em solução de tetrazólio, na concentração de $0,5 \%$, e mantidos à temperatura de $38^{\circ} \mathrm{C}$. Foram considerados viáveis os que apresentavam coloração vermelha uniforme em todas as estruturas. Os resultados foram expressos em porcentagem, considerando o número de pirênios utilizados nos testes de germinação, ou seja, 50 .

O experimento foi conduzido em delineamento inteiramente casualizado, com quatro repetições, obedecendo ao esquema fatorial 3 (clone) x 4 (tratamento pré-germinativo). Cada parcela foi representada por 50 pirênios. Consideraram-se as seguintes características na avaliação dos tratamentos: percentagem final de germinação 40 dias após a semeadura; percentagem de sementes viáveis ao final dos testes de germinação, tempo médio de germinação e número de plântulas obtidas a partir de 50 pirênios.

\section{RESULTADOS E DISCUSSÃO}

O número de sementes por pirênio nos clones Cristo e Santarém 2 variou entre zero e três, com frequência elevada de pirênios com mais de uma semente. Por outro lado, no clone Tocantins 1, os pirênios, com maior frequência, continham uma semente, com variações entre zero e duas (Tabela 1). A elevada frequência de pirênios com uma semente verificada nesse clone pode constituir-se em indicativo de sua maior capacidade de produzir frutos que completam a maturação quando apenas uma semente é formada. Potencialmente, todos os genótipos podem apresentar até três sementes por pirênio, em decorrência de que o ovário da flor é triloculado, e cada lóculo é uniovulado (BARROSO et al., 1999). Dessa forma, o número de sementes é 
dependente do número de óvulos fecundados e que apresentam desenvolvimento normal.

Conquanto se possa admitir que a frequência de pirênios com zero, uma, duas e três sementes tenha base genética, essa característica é fortemente dependente do ambiente, podendo variar, dentro de um mesmo clone, entre anos ou até mesmo entre amostras produzidas em diferentes épocas de um mesmo ano. No clone Cristo, por exemplo, Carvalho et al. (2006) verificaram, anteriormente, valores de $0 \%, 10 \%, 38 \%$ e $52 \%$ para pirênios com zero, uma, duas e três sementes, respectivamente. Esses valores, em particular no que concerne às porcentagens de frutos com uma e três sementes, divergem bastante dos valores aqui relatados para esse clone.

A ocorrência de pirênios de muruci desprovidos de sementes, independentemente do genótipo, foi ínfima, fato este já constatado por Carvalho e Nascimento (2008) em diásporos de outro genótipo. Na concepção desses autores, frutos com essa característica não se desenvolvem por partenocarpia, haja vista que a fecundação de, pelo menos, um óvulo, mesmo que o embrião em desenvolvimento venha a ser posteriormente abortado, constitui-se em fator essencial para a formação do fruto.

Conquanto a fecundação de um ou mais óvulos seja imprescindível para a conversão de flores em frutos, nem todos os ovários, em que um ou mais óvulos foram fecundados e posteriormente sofreram aborto, atingem o estádio de fruto maduro. Provavelmente, muitos frutos, nessa situação, sofrem abscisão antes de atingir a maturação. Esta hipótese é admissível, pois, quando não existem limitações bióticas e abióticas, são observadas elevadas taxas de fecundação de flores de murucizeiro, geralmente superior a $70 \%$, enquanto a taxa de conversão de flores em frutos maduros é bem menor, variando, de acordo com o genótipo entre $10,6 \%$ e $23,3 \%$ (CARVALHO et al., 2006).

No que se refere às características biométricas, observaram-se diferenças significativas para massa, comprimento, largura, diâmetro e número de sementes e de lóculos por pirênio $(\mathrm{p}<0,5)$, porém para a espessura da parede externa do endocarpo os valores obtidos foram estatisticamente equivalentes. Os pirênios do clone Cristo destacaram-se dos demais por apresentarem maior massa e maiores dimensões. O número médio de sementes por pirênio desse clone apresentou valor equivalente ao do clone Santarém 2 e superior ao do clone Tocantins 1. Os pirênios do clone Cristo também apresentaram maior número de lóculos, vindo a seguir os do Santarém 2 e Tocantins 1 (Tabela 2).
A presença de um ou mais lóculos desprovidos de sementes constitui-se em indicativo da ocorrência da fecundação de óvulos nesses lóculos, com o aborto das sementes em desenvolvimento, verificandose em fase já próxima de esta atingir a maturação fisiológica. Isto é suportado pelo fato de que, em lóculos em que não ocorre a fecundação de óvulos ou, ainda, em que o aborto do embrião se verifica nas fases iniciais de desenvolvimento, os tecidos do endocarpo não sofrem solução de continuidade, apresentando-se como massa compacta. Além disso, em muitos diásporos, foram observados resquícios de tecidos embrionários deteriorados e integumentos bastante desenvolvidos.

A aplicação de tratamentos pré-germinativos favoreceu a porcentagem de germinação das sementes de todos os clones. No entanto, respostas de maior magnitude foram obtidas quando os pirênios foram previamente embebidos em água ou em solução de ácido giberélico (500 $\left.\mathrm{mg} \mathrm{L}^{-1}\right)$ e posteriormente submetidos à fratura do endocarpo. Em todos os clones, quando se associou a pré-embebição em ácido giberélico com a fratura do endocarpo, as sementes germinaram mais rapidamente, atingindo o patamar de germinação aos 25 dias após a semeadura, momento em que as sementes do tratamentotestemunha apenas iniciavam a germinação (Figura 1). Em outras espécies do gênero Byrsonima, também tem sido constatado o efeito estimulante da pré-embebição dos diásporos em soluções de ácido giberélico sobre a germinação das sementes (Alberto et al., 2011; Murakami et al., 2011).

A pré-embebição dos pirênios, tanto em água como em solução de ácido giberélico, precedendo a fratura do endocarpo, é indicada devido ao fato de que o embrião da semente do muruci é espiralado e com a radícula bastante exposta (BARROSO et al., 1999), o que a torna bastante suscetível à injúria por quebramento quando se efetua a fratura do endocarpo, em particular quando os diásporos estão com baixo teor de água. Quando os pirênios são pré-embebidos antes da fratura do endocarpo, o embrião absorve certa quantidade de água e adquire elasticidade, o que permite que suas estruturas, particularmente a radícula que se encontra mais exposta, sofram flexões leves, reduzindo o risco de ser quebrada, conforme observaram Carvalho e Nascimento (2008). Em diásporos de Byrsonima cydoniifolia A. Juss, foi observado por Murakami et al. (2011), que a fratura do endocarpo teve efeito deletério sobre a porcentagem de germinação, porém, nesse caso, a fratura antecedeu à pré-embebição dos diásporos em solução de ácido giberélico.

A porcentagem final de germinação variou de 
acordo com o clone $(\mathrm{p}<0,05)$ e com os tratamentos pré-germinativos $(\mathrm{p}<0,05)$, havendo, porém, comportamento diferencial dos clones em relação aos tratamentos $(\mathrm{p}<0,05)$ (Tabela 3).

Quando os pirênios não foram submetidos a tratamentos pré-germinativos, maior porcentagem final de germinação foi obtida nas sementes do clone Cristo, indicando que, nesse genótipo, existe maior proporção de diásporos em que o endocarpo não oferece resistência mecânica restritiva à expansão do embrião, e as sementes não apresentam dormência fisiológica. Nos diásporos desse clone, o endocarpo constitui-se no principal mecanismo de resistência à germinação. Conquanto exista uma parcela de sementes fisiologicamente dormentes, a intensidade da dormência é baixa, o que é corroborado pelo fato de, ao se comparar a associação da pré-embebição em solução de ácido giberélico ou em água com a fratura do endocarpo, em ambos, a porcentagem de germinação foi equivalente. Por outro lado, nos diásporos dos outros dois clones, quando se combinou a pré-embebição em ácido giberélico com a fratura do endocarpo, a porcentagem de germinação foi bastante superior quando comparada com o tratamento envolvendo pré-embebição em água e fratura do endocarpo, indicando que os diásporos desses dois clones apresentam maior porcentagem de sementes dormentes (Tabela 3 ).

Não obstante o substancial aumento na porcentagem final de germinação verificada nos diásporos de todos os clones quando se provocou fratura no endocarpo, em particular quando a pré-embebição foi efetuada em solução de ácido giberélico, há de se considerar as grandes diferenças existentes na porcentagem final de germinação observada entre os clones. Essas diferenças, provavelmente, sejam decorrentes do fato de que diásporos de maior tamanho, como os do Cristo, são mais fáceis de serem manuseados durante a operação de fratura do endocarpo por compressão, sendo possível posicioná-los com firmeza na posição ápicebase sem provocar lesões nas sementes, seja por quebramento, seja por amassamento. Em diásporos do clone Açu, que são maiores que os do clone Cristo, elevadas porcentagens de germinação foram obtidas quando se utilizou como tratamento prégerminativo a fratura do endocarpo (CARVALHO; NASCIMENTO, 2008). Essa hipótese é corroborada pelos resultados dos testes de viabilidade (tetrazólio), haja vista que nos pirênios em que se provocou fratura do endocarpo e cujas sementes não germinaram, estas se apresentavam com viabilidade zero, ao contrário daquelas oriundas de pirênios com endocarpos intactos, cuja viabilidade foi alta (Tabela 4).
Nos clones Santarém 2 e Tocantins 1, o número de plântulas obtido a partir de 50 pirênios foi maior quando se combinou a pré-embebição em ácido giberélico com a fratura do endocarpo $(\mathrm{p}<0,5)$. Por outro lado, no clone Cristo, não se constatou diferença significativa para essa característica quando os pirênios foram pré-embebidos em água ou em ácido giberélico, com posterior fratura do endocarpo (Tabela 5). O fato de considerável proporção de pirênios submetidos à fratura do endocarpo por compressão no sentido do ápice para a base darem origem a mais de uma plântula, indica que esse procedimento, em muitos casos, condiciona fratura em mais de um lóculo, proporcionando pronta germinação das sementes.

Para o tempo médio de germinação, observouse comportamento diferencial das sementes dos diferentes clones em relação aos tratamentos pré-germinativos $(p<0,05)$. As sementes dos clones Santarém 2 e Tocantins 1 germinaram mais rapidamente, ou seja, apresentaram menor tempo médio de germinação, quando se associou a préembebição em solução de ácido giiberélico com a fratura do endocarpo. Respostas satisfatórias, em termos de redução do tempo médio de germinação, também se verificaram em pirênios pré-embebidos em água e com endocarpo fraturado, em particular nos do clone Cristo, em que esse tratamento não diferiu do anterior. Considerando-se o tempo médio de germinação dos diásporos dos três clones quando não se aplicaram tratamentos pré-germinativos, constata-se que os do clone Cristo foram os que apresentaram germinação mais rápida, vindo a seguir os do clone Santarém 2 e, por último, os do Tocantins 1 (Tabela 6).

A demonstração de que existem pronunciadas variações no grau de dormência de diásporos de diferentes clones é corroborada pelos resultados obtidos por Sautu et al. (2006) em diásporos de murucizeiro procedentes do Panamá, que obtiveram apenas $7,0 \%$ de germinação, 184 dias após a semeadura. 

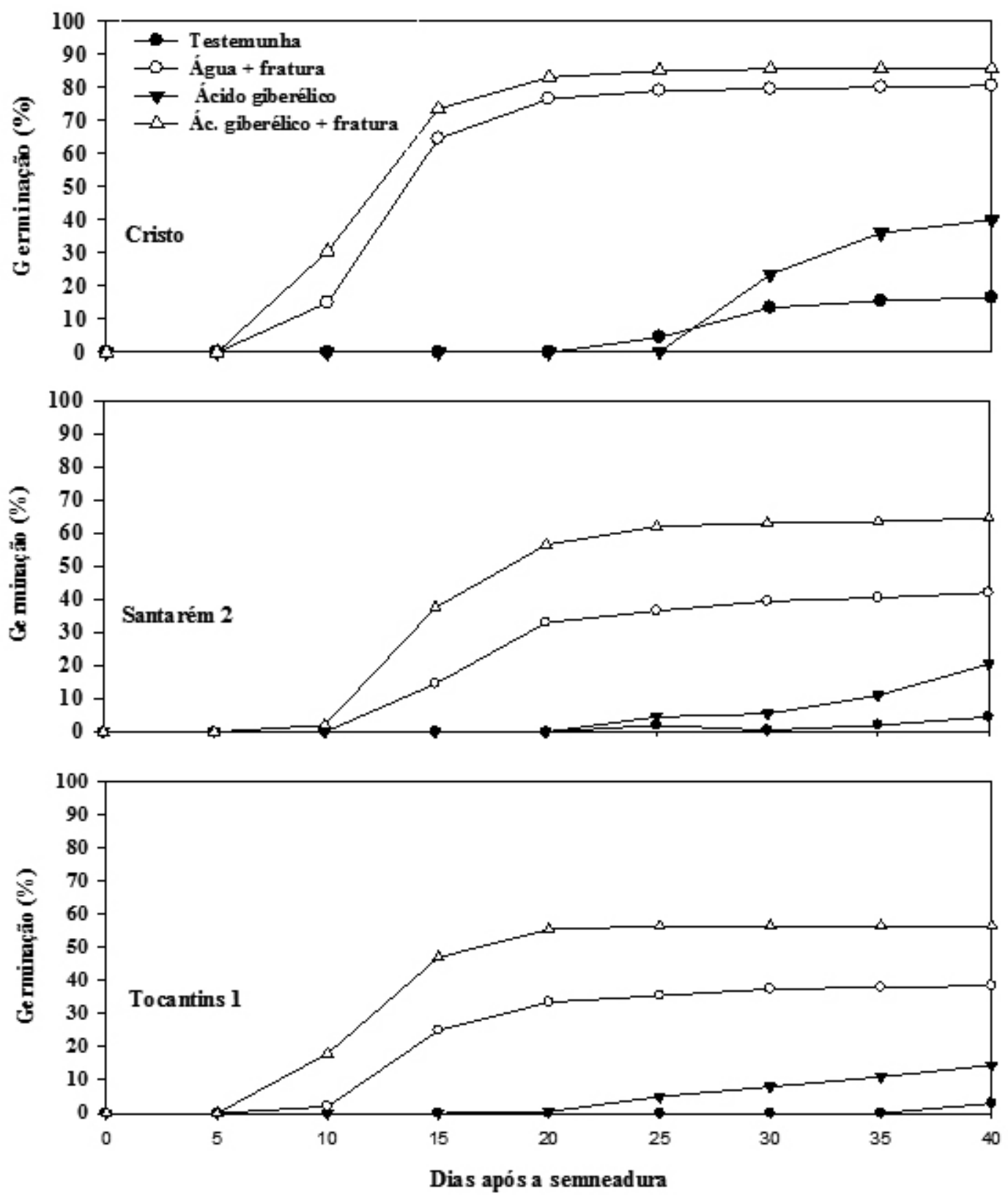

FIGURA 1 - Germinação de diásporos de murucizeiro dos clones Cristo, Santarém 2 e Tocantins 1 submetidas a tratamentos para a superação da dormência, em função do tempo (Byrsonima crassifolia (L.) H.B.K.). Belém-PA, 2011. 
TABELA 1 - Frequência (\%) do número de sementes em pirênios de quatro clones de murucizeiro (Byrsonima crassifolia (L.) HBK). Belém-PA, 2011.

\begin{tabular}{lcccc}
\hline \multirow{2}{*}{ Clone } & \multicolumn{4}{c}{ Número de sementes ${ }^{1}$} \\
\cline { 2 - 5 } & 0 & 1 & 2 & 3 \\
\hline Cristo & 1 & 44 & 42 & 13 \\
Santarém 2 & 4 & 32 & 49 & 15 \\
Tocantins 1 & 1 & 70 & 29 & 0 \\
\hline Média & 2,0 & 48,7 & 40,0 & 9,3 \\
\hline
\end{tabular}

1. $\mathrm{n}=100$.

TABELA 2 - Características biométricas e número médio de sementes e de lóculos em pirênios de três clones de murucizeiro (Byrsonima crassifolia (L.) HBK). Belém-PA, 2011.

\begin{tabular}{lcccccc}
\hline Clone & $\begin{array}{c}\text { Massa } \\
(\mathrm{g})\end{array}$ & $\begin{array}{c}\text { Comprimento } \\
(\mathrm{cm})\end{array}$ & $\begin{array}{c}\text { Largura } \\
(\mathrm{cm})\end{array}$ & $\begin{array}{c}\text { Espessura do } \\
\text { endocarpo }(\mathrm{mm})\end{array}$ & $\begin{array}{c}\text { Semente } \\
\left(\mathrm{n}^{\circ}\right)\end{array}$ & $\begin{array}{c}\text { Lóculo } \\
\left(\mathrm{n}^{\circ}\right)\end{array}$ \\
\hline Cristo & $0,38 \mathrm{a}^{1}$ & $1,12 \mathrm{a}$ & $0,86 \mathrm{a}$ & $1,3 \mathrm{a}$ & $1,7 \mathrm{a}$ & $2,5 \mathrm{a}$ \\
Santarém 2 & $0,34 \mathrm{~b}$ & $1,00 \mathrm{~b}$ & $0,79 \mathrm{~b}$ & $1,3 \mathrm{a}$ & $1,8 \mathrm{a}$ & $1,9 \mathrm{~b}$ \\
Tocantins 1 & $0,29 \mathrm{c}$ & $0,97 \mathrm{c}$ & $0,71 \mathrm{c}$ & $1,2 \mathrm{a}$ & $1,3 \mathrm{~b}$ & $1,6 \mathrm{c}$ \\
\hline CV $(\%)$ & 4,20 & 1,13 & 1,33 & 8,8 & 1,6 & 2,0 \\
\hline
\end{tabular}

1. Em cada coluna, médias seguidas pela mesma letra não diferem significativamente pelo teste de Tukey, ao nível de $5 \%$ de probabilidade.

TABELA 3 - Porcentagem final de germinação de diásporos de quatro clones de murucizeiro submetidos a tratamentos para a superação da dormência. (Byrsonima crassifolia (L.) H.B.K). Belém-PA, 2011.

\begin{tabular}{lcccccc}
\hline \multirow{2}{*}{ Clone } & \multicolumn{5}{c}{ Tratamento } & \multirow{2}{*}{ Média } \\
\cline { 2 - 5 } & Testemunha & Água + fratura & Ácido giberélico & Acido giberélico + fratura & \\
\hline Cristo & $15,5 \mathrm{Ca}^{1}$ & $80,5 \mathrm{Aa}$ & $40,0 \mathrm{Ba}$ & $85,5 \mathrm{Aa}$ & 55,4 \\
Santarém 2 & $4,5 \mathrm{Db}$ & $42,0 \mathrm{Bb}$ & $20,5 \mathrm{Cb}$ & $64,5 \mathrm{Ab}$ & 32,9 \\
Tocantins 1 & $3,0 \mathrm{Db}$ & $39,5 \mathrm{Bb}$ & $14,5 \mathrm{Cc}$ & $56,5 \mathrm{~A} \mathrm{c}$ & 28,4 \\
\hline Média & 7,7 & 54,0 & 25,0 & 68,8 & - \\
\hline
\end{tabular}

1.Em cada linha, médias seguidas pela mesma letra maiúscula, e em cada coluna, pela mesma letra minúscula, não diferem significativamente pelo teste de Tukey, ao nível de $5 \%$ de probabilidade.

TABELA 4 - Porcentagem de diásporos com, pelo menos, uma semente viável ao final dos testes de germinação. (Byrsonima crassifolia (L.) H.B.K). Belém-PA, 2011.

\begin{tabular}{lccccc}
\hline \multirow{2}{*}{ Clone } & \multicolumn{5}{c}{ Tratamento } \\
\cline { 2 - 5 } & Testemunha & Água + fratura & Ácido giberélico & Acido giberélico + fratura & \\
\hline Cristo & 80,0 & 0 & 64,0 & 0 & 38,0 \\
Santarém 2 & 90,0 & 0 & 70,0 & 0 & 40,0 \\
Tocantins 1 & 96,0 & 0 & 90,0 & 0 & 46,5 \\
\hline Média & 88,6 & 0 & 74,6 & 0 & - \\
\hline
\end{tabular}

TABELA 5 - Número de plântulas obtido a partir de 50 diásporos de murucizeiro (Byrsonima crassifolia (L.) H.B.K.) submetidos a tratamentos para a superação da dormência. Belém-PA, 2011.

\begin{tabular}{|c|c|c|c|c|c|}
\hline \multirow{2}{*}{ Clone } & \multicolumn{4}{|c|}{ Tratamento } & \multirow[b]{2}{*}{ Média } \\
\hline & Testemunha & Água + fratura & Ácido giberélico & Acido giberélico + fratura & \\
\hline Cristo & $8,3 \mathrm{Ca}^{1}$ & $51,8 \mathrm{Aa}$ & $25,0 \mathrm{Ba}$ & $59,8 \mathrm{Aa}$ & 59,8 \\
\hline Santarém 2 & $2,5 \mathrm{Db}$ & $25,0 \mathrm{Bb}$ & $12,5 \mathrm{Cb}$ & $44,3 \mathrm{Ab}$ & 44,3 \\
\hline Tocantins 1 & $1,8 \mathrm{Db}$ & $22,5 \mathrm{Bb}$ & $9,8 \mathrm{Cb}$ & $32,5 \mathrm{Ac}$ & 32,5 \\
\hline Média & 4,2 & 33,1 & 15,8 & 45,5 & \\
\hline
\end{tabular}

Em cada linha, médias seguidas pela mesma letra maiúscula, e em cada coluna,pela mesma letra minúscula, não diferem significativamente pelo teste de Tukey, ao nível de $5 \%$ de probabilidade. 
TABELA 6 - Tempo médio de germinação de diásporos de quatro clones de murucizeiro (Byrsonima crassifolia (L.) H.B.K.) submetidos a tratamentos para superação da dormência. Belém-PA, 2011.

\begin{tabular}{|c|c|c|c|c|c|}
\hline \multirow{2}{*}{ Clone } & \multicolumn{4}{|c|}{ Tratamento } & \multirow{2}{*}{ Média } \\
\hline & Testemunha & Água + fratura & Ácido giberélico & Acido giberélico + fratura & \\
\hline Cristo & $27,6 \mathrm{Ac}^{1}$ & $13,0 \mathrm{Bc}$ & $29,4 \mathrm{Ab}$ & $12,1 \mathrm{Bb}$ & 20,5 \\
\hline Santarém 2 & $32,7 \mathrm{Ab}$ & $18,5 \mathrm{Ba}$ & $33,2 \mathrm{Aa}$ & $15,9 \mathrm{Ca}$ & 25,1 \\
\hline Tocantins 1 & $38,8 \mathrm{Aa}$ & $16,2 \mathrm{Cb}$ & $29,4 \mathrm{Bb}$ & $12,6 \mathrm{Db}$ & 24,3 \\
\hline Média & 33,0 & 15,9 & 30,7 & 13,5 & - \\
\hline
\end{tabular}

1. Em cada linha, médias seguidas pela mesma letra maiúscula, e em cada coluna,pela mesma letra minúscula, não diferem significativamente pelo teste de Tukey, ao nível de $5 \%$ de probabilidade.

\section{CONCLUSÕES}

1-O principal mecanismo de resistência à germinação de diásporos de muruci é representado pelo córneo endocarpo, que oferece restrições à expansão do embrião.

2-A pré-embebição de diásporos de muruci em água e, especialmente, em solução de ácido giberélico $\left(500 \mathrm{mg} \mathrm{L}^{-1}\right)$ seguida de fratura do endocarpo, favorece a germinação de sementes de muruci.

3-A intensidade da dormência e as respostas fisiológicas de diásporos de murucizeiro variam de acordo com o clone.

\section{REFERÊNCIAS}

ALBERTO, P.S.; SILVA, F.G.;CABRAL, J.S.R.; SALES, J. de F.; PEREIRA, F.D. Methods to overcome of the dormancy in muruci (Byrsonima verbascifolia Rich) seeds. Ciências Agrárias, Londrina, v. 32, n.3, p.1015-1020, 2011.

ALVES, G.L.; FRANCO, M.R.B. Headspace gas chromatography-mass spectrometry of volatile compounds in murici (Byrsonima crassifolia L. Rich). Journal of Chromatography, Amsterdam v.985, n.1-2, p.297-230, 2003.

BARROSO, G.M.; MORIM, M.P.; PEIXOTO, A.L.; ICHASO, C.L.F. Frutos e sementes: morfologia aplicada à sistemática de dicotiledôneas. Viçosa: UFV, 1999. 443p.

CARVALHO, J.E.U. de; MÜLLER, C.H. Biometria e rendimento percentual de polpa de frutas nativas da Amazônia. Belém: Embrapa Amazônia Oriental, 2005. 4p. (Comunicado Técnico, 139).
CARVALHO, J.E.U. de; NASCIMENTO, W.M.O. do. Caracterização dos pirênios e métodos para acelerar a germinação de sementes de muruci do clone Açu. Revista Brasileira de Fruticultura, Jaboticabal, v.30, n.3, p.775-781, 2008.

CARVALHO, J.E.U. de; NASCIMENTO, W.M.O. do; MÜLLER, C.H. Propagação do murucizeiro. Belém: Embrapa Amazônia Oriental, 2006. 27p. (Documentos, 261).

CAVALCANTE, P.B. Frutas comestíveis na Amazônia. 7.ed. Belém: Museu Paraense Emílio Goeldi, 2010. 282p. (Coleção Adolpho Ducke).

CLEMENT, C.R. 1492 and the lost of Amazonian crop genetic resources. Crop biogeography at contact. Economic Botany, Bronx, v. 53, n.2, p.203-216, 1999.

MURAKAMI, D.M.; BIZÃO, N.; VIEIRA, R.D. Quebra de dormência de sementes de murici. Revista Brasileira de Fruticultura, Jaboticabal, v. 33, n.4, p.1257-1265, 2011.

NASCIMENTO, I.L. do; LEAL, C.C.P.; NOGUEIRA, N.W.; MEDEIROS, A.K.P. de; CÂMARA, F.M.M. Uso de metodologias variadas na quebra de dormência de sementes de muruci. Revista Verde de Agroecologia e Desenvolvimento Sustentável, Mossoró, v.6, n.3., p.226-230, 2011.

SAUTU, A.; BASKIN, J.M.; BASKIN, C.C.; CONDIT, R. Studies on the biology of 100 native species of trees in a seasonal moist tropical forest, Panama, Central America. Forest Ecology and Management, Fort Collins, v. 234, p.245-263, 2006. 
SILVA, E.M.; SOUZA, J.N.S.; ROGEZ, H.; REES, J.F.; LARONDELLE, Y. Antioxidant activities and polyphenolic contents of fifteen selected plant species from the Amazonian region. Food Chemistry, Reading, v.101, n.3, p. 1012-1018, 2007.

SOUZA, F.M.; SOARES JÚNIOR, F.J.;TEIXEIRA, A. de P. Diversidade e similaridade florística em cinco fragmentos de cerrado no município de Itirapina-SP. Disponível em: < www.ib.unicamp. br/profs/fsantos/relatorios/he211b.pdf $>$. Acesso em: 10 out. 2010 .
SOUZA, J.N.S.; SILVA, E.M.; LOIR, A.;REES, J.F.; ROGEZ, H.; LARANDELLE, Y. Antioxidant capacity of four polyphenol-rich Amazonian plant extracts: A correlation study using chemical and biological in vitro assays. Food Chemistry, Reading, v.106, n.1, p. 331-339, 2008. 